\title{
Prices for Local Area Network Equipment
}

Mark Doms

Federal Reserve Bank of San Francisco

Chris Forman

Graduate School of Industrial Administration, Carnegie Mellon University

June 2003

Please send correspondence to mark.doms@sf.frb.org or cforman@andrew.cmu.edu.

We are grateful to Carol Corrado, Shane Greenstein, Jack Triplett, and participants at the Brookings Workshop on Communications Output and Productivity and 2001 NBER Summer Institute for helpful comments and assistance. We wish to thank Jason Coburn, Jonathan Eller and Susan Polatz for outstanding research assistance. We also wish to thank Gregory Goldstein and Robert Drzyzgula for sharing their expertise about computer networks. The statements and results in this paper do not necessarily reflect the views of the Federal Reserve. 


\begin{abstract}
In this paper we examine quality-adjusted prices for local area network (LAN) equipment. Hedonic regressions are used to estimate price changes for the two largest classes of LAN equipment, routers and switches. A matched model was used for LAN cards and the prices for hubs were inferred by using an economic relationship to switches. Overall, we find that prices for the four groups of LAN equipment fell at a 17 percent annual rate between 1995 and 2000. These results stand in sharp contrast to the PPI for communications equipment that is nearly flat over the 1990 s.
\end{abstract}

Key words: price index; hedonic; communications equipment 


\section{Introduction}

Local area networking (LAN) equipment routes information between computers and plays a part in every message sent and received over the Internet. Rapid technical change in LAN equipment and the subsequent declines in prices was one of the necessary ingredients to the widespread diffusion of computer networks and the explosion in the popularity of the Internet.

As can be seen in table 1, nominal spending on LAN equipment grew very rapidly during the 1990s, complementing investments in computers and peripherals and in software. In 1991, spending on LAN equipment was below $\$ 2$ billion. By 2000, sales of LAN equipment in the United States totaled close to $\$ 16$ billion dollars to become one of the single largest categories within communications equipment. One could argue that without the technological advances in LAN equipment, communication would be much costlier than it is today, and the benefits society has received from the information technology revolution would be significantly reduced.

Although technical change in LAN equipment was one of the key inputs to the spurt in information technology investment in the late 1990s, there has been no prior work to measure price changes in LAN equipment. Previous authors have shown that lack of accurate price data can have important implications for estimating growth and productivity. For instance, Jorgenson and Stiroh (2000) found that changing the estimated rate of price declines in communications equipment could add nearly 0.1 percentage point to average annual GDP between 1990 and 1998. ${ }^{1}$

Given the importance of LAN equipment, we investigate the rate of price declines in LAN equipment in the late 1990s. We present the results of an analysis of price changes for four of the most important types in LAN equipment: routers, switches, LAN cards, and hubs. We use hedonic regressions to estimate price changes for the two largest classes of LAN equipment, routers and switches. We use matched models for LAN cards and the prices for hubs were inferred by using an economic relationship to switches. We use manufacturer product catalogs and third-party product reports to estimate hedonic regressions, and use privately compiled price estimates in our matched models. Gathering the data for this project was difficult, and the difficulty no doubt help explains why there has not been more work in this area. In fact, one can view this project as one small battle in the "house-to-house" combat that is necessary to improve

\footnotetext{
${ }^{1}$ Other authors have shown how the lack of accurate price data for consumer goods has led to mismeasurement of the CPI. See, for example, Boskin et. al. (1996) and Hausman (1999).
} 
price measures that are used in the National Income and Product Accounts (Shapiro and Wilcox 1996). ${ }^{2}$

Our results show that price declines in LAN equipment were robust, with a sizable impact on estimates on the real growth in communications equipment investment. We find that prices of the four groups of LAN equipment fell at double-digit rates in the last half of the 1990s. Routers fell an average of about 14 percent between 1995 and 1999, although results vary considerably across router classes. Prices for switches fell faster than routers, averaging an annual decline of about 22 percent. The prices for LAN cards dropped at an annual average rate of 18.3 percent. We estimate that the prices for hubs, the smallest portion of the LAN category, fell an average of 19 percent. Between 1995 and 1999, our estimate of the price index for all LAN equipment fell an average of 17 percent--pulled down by switches and hubs but held up by routers. These results stand in sharp contrast to the PPI for communications equipment that is nearly flat over the 1990s, and would create an upward revision to real investment growth rates for communications equipment and non residential investment of 2.4 and 0.2 percentage points, respectively.

We show that price declines vary a great deal over different segments of the router market. We discuss how this variation depends on factors such as market concentration, switching costs, and the penetration of the new technology. Although we are unable to test the relationship, our data are unique because they suggest how switching costs can affect the rate of price declines at different stages in the diffusion of a new technology. Thus, our paper also contributes to the recent hedonic literature examining the relationship between market structure and price declines. ${ }^{3}$

\section{Local Area Networks}

\section{II.1. Overview of LAN equipment}

The basic manner in which LAN equipment transmits data packets is similar to that which circuit switches use to transmit voice messages. A common language, or protocol, is used so that communications can be sent from a sender to a receiver. This language is translated by various means into a signal that travels over a physical medium, such as copper wire, fiber optic

\footnotetext{
${ }^{2}$ In fact, the results presented in this paper have already been incorporated by the Bureau of Economic Analysis in the GDP statistics.
} 
cable, or over the airwaves. Because of the physical impossibility of maintaining direct communications links between every possible sender and receiver of data, network traffic travels over the physical medium through a series of nodes that, like circuit switches in the telephone communications infrastructure, act to guide and regulate traffic over the network.

LAN equipment directs traffic between computers, making possible email transmissions, Internet browsing, and file sharing with co-workers. LANs are used to connect small groups of users who are usually located physically close to one another and who may often wish to utilize a shared resource such as a printer or some other peripheral. Users in a LAN are often grouped not only physically but also functionally, so that the most frequent contacts for a user within a LAN will usually be other users within the same LAN.

To make some sense of the various LAN devices, figure 1 has a simplified and partial diagram of a prototype network for a company. We use this diagram to describe the four classes of LAN equipment we study: routers, switches, LAN cards, and hubs. When an email is sent from a computer in the Marketing Division (the bottom right of the figure), the computer breaks the message into pieces, called packets. The packets are sent through the computer's LAN card, a device that physically connects the PC to the computer network. The packets then go to a switch. Switches act as filters, making decisions on where a packet should go. For instance, if a file is to be printed, the packets of information can stay in the LAN and are not sent out to the broader network. Switches operate like circuit switches in the public telephone network, acting as nodes that take incoming traffic and redirect it to its final destination. Switches are advanced products, sometimes containing hundreds of ports and capable of redirecting millions of packets of information a second.

The switch sends the email message to a router that oversees the Marketing Division. Routers are usually the "brains" behind any network. A router is a sophisticated device that decides how packets should travel through the network. If the message is intended for a coworker, the router sends the message back down the network. In the case of an email to someone outside the site, the message will be sent along a fiber optic loop, hit another router, and is sent out to the Internet.

Like switches, routers direct packets of information across a network. However, differences in the ways that routers and switches work give routers some added functionality

\footnotetext{
${ }^{3}$ See, for example, Gandal (1994), Brynjolfsson and Kemerer (1996), and Harchaoui and Hamdad (1995).
} 
over switches. Routers are able to optimize network traffic, and are able to determine the best path for a packet traveling through the network. Routers have management and security features. Network managers use routers to identify congestion within a network, and use security features in routers to keep networks safe from hackers.

When an email is sent from one of the member of the Research Division (the bottom left portion of the figure), packets are again sent through a LAN card. They next travel to a hub. Hubs are used to connect computers in a LAN, or to allow many computers to share a network line. Hubs perform similar tasks as routers and switches. Unlike switches or routers, however, hubs do not filter packets. While still commonly used, hubs are much simpler devices than either routers or switches, generally lacking many of the management features as well as the filtering capabilities of those products.

\section{II.2. Growth in Data Communications Equipment Spending}

By the early 1990s, sales of LAN equipment soared, boosted by the migration of corporate information systems from mainframe to client/server $(\mathrm{C} / \mathrm{S})$ computing platforms. Figure 2 shows the growth in end user spending on LAN equipment. Routers, hubs, and LAN cards had been introduced years before in the 1980s. Sales of routers continued to grow steadily, driven in part by the growing popularity of the Internet. Sales of LAN cards eventually flattened as the number of new network nodes began to reach saturation and continued declines in prices muted revenue gains. Sales of hubs climbed then fell as switches slowly supplanted them.

Switches became popular in 1994 as a solution to increasing congestion that was plaguing corporate networks and the Internet. The technology underlying the brainy routers, although important to generating the features that had made them so successful, was judged too slow in some instances to route the increasing volume of traffic in high-speed networks. As figure 2 shows, switches have grown explosively since 1994, becoming by far the fastest growing segment among LAN equipment.

However, despite this rapid growth - and the large body of work that has calculated quality-adjusted prices for computers and peripherals - there has been very little measurement work on communications equipment and no prior study examining LAN prices. ${ }^{4}$ Government

\footnotetext{
${ }^{4}$ For prior research on computer prices see, for example, Cole et. al. (1986), Berndt, Griliches, and Rappaport (1995), Berndt and Rappaport (2001), Chwelos (2001).
} 
statistics that measure price changes in communications equipment use matched model techniques that may fail to adequately capture quality change. Figure 2 shows that among LAN equipment, the fastest rate of growth occurred among routers and switches, classes of equipment for which product complexity and rapid technical change make quality adjustment most difficult.

\section{II.3. Previous Prices for LAN and Communications Equipment}

We explore prices for LAN equipment because there is a widespread belief that official measures for prices in the more aggregate category of communications equipment do not accurately capture quality changes. ${ }^{5}$ This belief stems from two major sources. First, prior research in related areas of telecommunications equipment (telephone switches) showed qualityadjusted prices fell much faster than had previously been measured by government statistics (Flamm 1989; Grimm 1996). Second, LAN equipment shares several inputs with other high-tech products. Many of these inputs, such as semiconductors, have had rapid rates of price declines. Once we get a better handle on what has happened to prices for LAN equipment, we will then be better able to address questions on how investment in communications equipment affects output measurement, and how communications equipment investment may be related to the acceleration in aggregate productivity growth observed in the late 1990s.

Table 2 presents summaries of some official price measures for communications equipment and computers during the past decade. The table shows the average annual percent change in prices for the selected series for the 1990-1995, 1995-2000, and the 1990-2000 periods. The PPI for overall communications equipment grows slightly ( 0.3 percent per year) over the 1990s. The PPI does not have a category for LAN equipment. The PPI category most similar to LAN is equipment is "other data communications equipment," which was compiled between 1995 and 2000. The prices for this category decreased at an average rate of 0.1 percent, slightly slower than the overall communications equipment aggregate over this time period. The deflator BEA uses for its PDE communications equipment category falls faster, declining 1.8 percent between 1995 and $2000 .^{6}$

In sharp contrast to the official prices indexes for communications equipment, the official prices for computers have fallen very rapidly in the 1990's. Between 1995 and 2000, the BEA

\footnotetext{
${ }^{5}$ For instance, such claims are made by Gordon (1990) and Jorgenson and Stiroh (2000).
} 
measure for PDE computer prices fell an average of over 22 percent. This faster rate of decline is due to the work government statistical agencies have done using hedonics to adjust for quality change in computers.

\section{II.4. Market Structure in LAN Equipment}

As we show below, the increasing concentration of the market for LAN equipment may have influenced the evolution of prices. Like many infant industries, the market structure for LAN equipment was very fragmented during the formative years of its evolution. However, as the industry matured in the $1990 \mathrm{~s}$, this quickly changed. A small number of hardware firms, lead by Cisco Systems (hereafter referred to as Cisco), 3Com, Bay Networks, and Cabletron, came to dominate most segments of the market. ${ }^{7}$ As the market matured, the technical features of individual products (such as processor speed and memory) were increasingly less important to buyers. More important were demand-side notions such as ease of installation and integration with existing systems, and broader measures of customer service and technical support. The increasing importance of these "softer" product characteristics favored a more concentrated market structure.

As noted above, this pattern of "shakeout" is common in new industries, and has been explored extensively in prior research (e.g., Gort and Klepper 1982; Klepper 1996). In the LAN equipment industry, there is evidence that shakeout occurred because of users' desire for interoperability across LAN equipment devices. In the early 1990s there was a proliferation of new products and vendors, but little standardization across products in things such as software, protocols, and hardware interfaces. This lack of standardization made network management and design difficult. Networking vendors claimed to support common protocols such as Ethernet or TCP/IP, however in practice products were often incompatible. ${ }^{8}$ Since many firms only offered a small range of LAN equipment products, buyers incurred sizable switching costs when purchasing from multiple vendors. Moreover, while the underlying technology of LAN equipment was improving tremendously, levels of service provided by vendors to configure and

\footnotetext{
${ }^{6}$ One reason that the BEA Communications Equipment index fall faster is that it is based in part on a hedonic price index for digital telephone switches developed by Grimm (1996).

${ }^{7}$ Nortel acquired Bay Networks in 1998 to become Nortel Networks.

${ }^{8} \mathrm{TCP} / \mathrm{IP}$ is the primary protocol used to transmit messages through the Internet. For evidence on interoperability problems among LAN equipment see, e.g., Bunnell (2000).
} 
maintain systems were not. New start-up firms had the technology to provide impressive new products, but did not have the staff or the training to provide support.

Many users hoped to eliminate interoperability problems by purchasing from fewer vendors. They also wanted greater service and support from their vendors. These buyer demands, combined with the strong cash flows and high stock values of LAN firms, helped ignite a wave of consolidation in the industry. The trend towards industry consolidation, as well as the industry practice of major players acquiring industry start-ups to fill gaps in existing product lines, was further boosted by the introduction of LAN switches. Existing players who had no switch offering, such as Cisco, rapidly acquired smaller switch producers. For example, in 1996 Cisco paid $\$ 4.7$ billion for StrataCom Incorporated, a producer of switches, to gain entry into the market for LAN switches. More recently, LAN equipment manufacturers made multibillion dollar acquisitions in 2000 and 2001 to gain access to optical technologies.

Consolidation eventually became so extensive that one firm, Cisco, dominated large parts of the LAN equipment industry. Table 3 a presents the top four firms in the four major areas of LAN equipment for 1996 and 1999. Cisco's market share in routers and switches increased steadily; by 1999, Cisco had 77 percent of the router market. Cisco also had a large presence in the switch market, although not as large as that for routers. In 1996, Cisco commanded about 30 percent of LAN switch sales, and by 1999 that figure had increased to about 47 percent.

\section{Price Indexes for Routers}

In this section we describe and present results from a hedonic analysis of routers. We use hedonic regressions instead of matched model price indexes because of frequent entry and exit of models between sampling periods in our data. Frequent entry and exit of products makes matching difficult and creates a "new goods" bias, a problem that results in price indices being overstated. Use of hedonic regressions alleviates some of the new goods bias by redefining goods in terms of their characteristics and estimating the rate of price change, controlling for the set of observable product characteristics. Because the effects of the new goods bias worsens as the time frame of the sampling period increases, use of hedonic regressions may be especially propitious when you are unable to sample frequently (Aizcorbe, Corrado, and Doms 2000). Our data on routers is annual, and there are many products that enter and exit the market during the course of a year. 
However, it is well known that hedonic methods are not without their own problems. For instance, Trajtenberg (1989) and Pakes (2002) note there are several aspects of the new goods problem that increase consumer utility but are not reflected in price indexes generated from hedonic regressions or matched models. Hedonic based price indexes are also generally unable to provide an exact measure of the consumer welfare generated by quality change in a good. ${ }^{9}$ The results from the hedonic method can unfortunately vary depending on the set of right hand side variables and model specification. With those usual caveats in mind, the hedonic method is well known and is one of the most common methods employed for estimating qualityadjusted price changes. Moreover, the data requirements and equilibrium assumptions for hedonics are less stringent than those used in models that calculate the compensating variation directly by estimating consumer preferences and market equilibrium. ${ }^{10}$

\section{III.1 Data and characteristics selection}

The hedonic method requires data on the prices and characteristics of the goods in question. While hedonic studies of IT goods like PCs often use data from magazines (e.g., Chwelos 2001; Nelson et. al. 1994) or data from third-party consultants (e.g., Berndt, Griliches, and Rappaport 1995; Pakes 2002), these sources were inadequate for our purposes. These sources typically contained too few models to construct a reasonable sample, contained little information on product characteristics, and often contained products that were not representative of the market (in particular Cisco, by far the largest vendor, was typically underrepresented). ${ }^{11}$ Instead of these more traditional sources, we collected data from Cisco catalogs for the summer quarters of 1995-1998. Prices for 1999 were collected directly from the firm's World Wide Web site. $^{12}$ Our data are exclusively from Cisco. However, Cisco's market share varied from 59.5 percent to 73.5 percent over our sample period, so that our data should be representative of price movements in the market. We were unsuccessful in obtaining comparable data for routers made by other firms.

\footnotetext{
${ }^{9}$ Feenstra (1995) identifies the circumstances under which hedonic regressions can provide an exact measure of the change in consumer welfare. Pakes (2002) shows that hedonic price indexes can bound the true compensating variation.

${ }^{10}$ See, for example, Trajtenberg (1989), Petrin (1999), and Nevo (2000).

${ }^{11}$ For a more complete discussion of the problems of these data sources, as well as a broader discussion of our data collection methods for routers, see Forman and Doms (1999).

12 The prices are list rather than transaction prices. However, after speaking with industry participants, we have found little evidence that the gap between list and transaction prices have changed significantly over time.
} 
A second issue related to the proper unit of observation: system or component. While low end routers often came completely pre-assembled, buyers often had great flexibility in choosing the features bundled with midrange and high end routers. Among these higher end product classes, buyers could often choose between over 40 interface modules that supported different networking protocols, and buyers had wide latitude in deciding the number of modules they purchased. Given a choice of router model, buyers could also decide between varying memory, power sources, and input/output controllers. We were unable to estimate price indexes for individual router components because for some product characteristics, the location of the characteristic (e.g., processor box or module) varied by model. ${ }^{13}$ As a result, we considered only routers that were "fully loaded" with modules. In other words, all routers in the regression were configured with as many modules as the machine had available ports. ${ }^{14}$ In general, all routers considered were configured with a processing engine, memory, interface ports or modules, and an input/output controller. Software was generally not included because yet we had no way of controlling for quality differences in software products. ${ }^{15}$ In cases where multiple configurations were available for a given component (i.e., the amount of memory included in the router or the type of interface module), we would consider models with all possible configurations. Prices were determined by summing the list prices of all components.

Following industry convention, we break our data into four major categories of routers: Small Office/Home Office (SOHO), Low End, Midrange, and High End. Small Office/Home Office routers are personal models designed primarily to connect a remote user to the corporate network. ${ }^{16}$ Branch offices of corporations use Low End models to organize traffic within the branch and to connect branches to a corporate network. Midrange routers are the brains behind many small to mid-size corporate networks, and High End routers are typically used only by large multinational corporations or Internet Service Providers (ISPs). More recently, multigigabit routers have come onto the market, but there was not enough data on these routers to

\footnotetext{
${ }^{13}$ Chwelos (2001) shows that estimating hedonics of systems of components in microcomputers may yield different answers than aggregating the results of individual estimations. The reason is potential interaction between system components. Here we aggregate to the system level because of heterogeneity in the location of characteristics across routers.

${ }^{14}$ Some interface modules were built so that additional modules could, in turn, be built on to them. We did not consider routers with this extra layer of "add-ons," as such further add-ons tended to be the exception.

${ }^{15}$ In a small number of cases, list prices included a bundled version of Cisco's Internetworking Operating System (IOS) software, thus prices by necessity included the price of software.

${ }^{16}$ More recently, routers in this category have been used to set up home networks, whether they be wired or wireless.
} 
include in our analysis. Also, these multi-gigabit routers would have been a very small portion of the router market for the time period we examine.

We use engineering data on the main components of the router as our characteristics variables. ${ }^{17}$ Table $4 \mathrm{~A}$ lists these variables used along with their means and standard deviations by router class. Bandwidth measures the theoretical maximum bandwidth, measured in megabits per second (Mbps), that the router is capable of networking. In other words, Bandwidth represents the total amount of network data that can be sent to the router at one time, and is found by summing the theoretical maximum data throughput from each of the cables connected to the router. The Bandwidth variable is a measure of the data capacity capable of being sent through the router, however it says nothing about the speed with which that data will be processed.

Other variables include the number of ports available for network interface modules, processor speed, standard DRAM memory, and FLASH memory. Processor speed is measured in megahertz, while DRAM and FLASH memory are measured in megabytes. We also include a dummy variable that indicates whether the router has a DC power source.

We also include dummy variables to indicate the year and market segment of a particular router. Table 4B provides a list of the dummy variables and their sample means. We include time dummies for 1995, 1996, 1998, and 1999. We also include dummies that indicate whether the router is included in the SOHO, Low End, Midrange, or High End markets. The last dummy in the table is one if the router is in the Midrange or High End of the market and zero otherwise, and will be used to allow coefficients on the characteristic variables to vary across different parts of the product spectrum.

\section{III.2. Hedonic estimation and results}

The hedonic method provides little guidance in the way of a priori restrictions on specification of the model. We confront three major specification issues. First, there are a variety of functional forms from which to choose. Like many other hedonic studies, we

\footnotetext{
${ }^{17}$ As in hedonic studies of computers, there exist two classes of attributes that one may use for the vector of characteristics. One class of characteristics variables uses data from performance studies to measure attributes such as the speed of the device (in our case, packet throughput) or, perhaps, reliability (in the case of routers, packet loss rate). A major problem with the use of such benchmark studies is that the manufacturers themselves often sponsor them. Under these conditions, it is unsurprising that the "best" router is usually the one from the manufacturer sponsoring the study.
} 
consistently found that log-log models were superior to other functional forms and only those results will be discussed. ${ }^{18}$ Second, there is a question as to whether the relationship between prices and characteristics is stable across the four major router product classes. Last, we ask if the shadow prices of product characteristics are constant through time. Given the vast technical change in these products, consumers' valuation of characteristics may have changed as product characteristics have improved. The last two specification issues are addressed in the two sections below.

\section{III.2.1. Parameter stability across router classes}

We expect there is likely to be some difference in buyer's valuation of product characteristics across product classes, particularly between the very high and low ends of the product spectrum. As noted above, routers at either extreme of the product spectrum serve very different purposes and target very different audiences, implying, as Triplett (1989) notes, that the contour of the hedonic surfaces are likely to be different. ${ }^{19}$

One way of testing the hypothesis of parameter stability is to compute F-tests. However, as Berndt, Griliches, and Rappaport (1995) note, when samples are large and standard test procedures employed (as they are in this case), F-tests may reject simplifying parameter restrictions on purely statistical grounds. We follow their procedure of applying 0.01 significance levels to F-tests and examine the change in root mean squared error (RMSE) to determine whether the hypothesis of parameter stability should be rejected. As in their paper, we require two conditions to reject the hypothesis of parameter stability: (1) the p-value of the F-

\footnotetext{
${ }^{18}$ We compared the results of seven different functional forms using standard goodness-of-fit measures. Further description on this, as well as our analysis of parameter stability across products and time, is provided in Forman and Doms (1999).

19 To see this, it may be useful to examine an example. Consider the cost of an ethernet port across the four categories in our data in 1999. In our hedonic regressions, because ethernet lines have bandwidth of $10 \mathrm{Mbps}$, this would translate into the cost of $10 \mathrm{Mps}$ of $B A N D W I D T H$. In the High End sample, a 6-port ethernet processor module configured for a High End Cisco 7500 router had a list price of \$16,000, for an approximate cost of $\$ 2666.67$ per ethernet port. Among the 7200 series routers, which are included in both the High End and Midrange samples, the cost of a 4-port ethernet module was $\$ 4500$, or $\$ 1125$ per port. However, in the Low End of our sample, the cost of a complete Cisco 2501 router which included both an ethernet and two serial ports was \$995, while in the SOHO category the cost of a complete Cisco 1005 router with one ethernet and one serial port was $\$ 395$. Although the conclusions one can draw from an example such as this are limited, it does suggest one should be careful about assumptions of parameter constancy.
} 
tests must be less than .01 and (2) the change in RMSE from moving to an unrestricted regression must be greater than $5 \%$.

We divided our sample into high end (consisting of High End and Midrange) and low end (consisting of Low End and SOHO) products and test for parameter constancy across the two groups. The results suggested we should allow parameters to vary across the two sample groups. We also investigated the hypothesis that the coefficients on the characteristics variables should be allowed to vary across all four segments. Unfortunately, in the early years of the sample there was insufficient variation in the product characteristics variables within a given segment and year to obtain reliable parameter estimates.

In our baseline model we allow parameters to vary between the higher (High End and Midrange) and lower (SOHO and Low End) ends of the product spectrum but not across all product classes. This specification also fits within our knowledge of the industry. The lower end of the spectrum, consisting of the SOHO and Low End segments, consist primarily of selfcontained routers selling mostly for under $\$ 3,000$. Branch offices and individuals use these models to connect to a corporate network. In contrast, the Midrange and High End segments serve as the "brains" behind a firm's central corporate network; their prices can sometimes run into hundreds of thousands of dollars. We expect the relationship between parameters and price to vary across these two groups. However, the dividing line between SOHO and Low End products and between Midrange and High End is often unclear. In fact, our classification system, which is the same used by industry consulting group Dataquest, places some model series in two different market segments. ${ }^{20}$ For instance, the determination of whether a Cisco 1600 series belongs in the SOHO or Low End category depends on whether the router includes an optional WAN Interface Card (WIC). Moreover, the Cisco 7202 and 7204 models, both members of the 7200 series, are included within the Midrange group, while the 7206 is classified as a High End product.

\section{III.2.2. Parameter stability through time}

There are typically three methods used to estimate hedonic regressions. First, one can estimate yearly regressions and allow parameter estimates to vary by year. Second, one can 
estimate pooled regressions holding coefficients constant over adjacent two-year time periods. Last, one can estimate a single pooled regression over the entire sample period. Estimating pooled regressions will, of course, have the advantage of improved efficiency if the hypothesis of parameter stability is correct. Pakes (2002) notes that while pooled regressions sometimes engender a bias because of shifts in the hedonic surface over time, they will sometimes be preferred when sample sizes are small and the bias is more than compensated by lower variance in the estimated price index. ${ }^{21}$

To examine the hypothesis of parameter stability through time we again use F-tests and examine the change in RMSE by moving from the restricted to unrestricted regression estimates. We first examine the hypothesis of parameter stability across all four years. F-tests reject this hypothesis at greater than the $1 \%$ level, and the change in RMSE is over $9.6 \%$. The comparison between our yearly and adjacent years regression models is not as clear cut; F-tests reject the hypothesis of parameter stability at the one percent level in all cases, however the improvement in RMSE is often less than the 5\% level suggested by Berndt, Griliches, and Rappaport (1995). Because of this, this section will present the results from the adjacent year regressions. ${ }^{22}$

\footnotetext{
${ }^{20}$ Cisco divides its product line both into product series and then models within that series. For instance, the Cisco 2501 is a particular model within the 2500 series. Models within the same series often share common characteristics, such as memory or processor speed.

${ }^{21}$ Recent papers have examined the incidence of parameter stability in hedonic regressions and the implications for price index measurement. Berndt and Rappaport (2001) find evidence of parameter instability in desktop and laptop PCs. Heravi and Silver (2002) use scanner data to examine the incidence of parameter instability in a variety of household goods, and find evidence of instability and noticeable effects on imputed Laspeyres and Paasche price indexes.

${ }^{22}$ Results of each of the tests and yearly regressions are included in Forman and Doms (1999).
} 


\section{III.2.3. Router results}

Table 5 presents the results from the adjacent year regressions. These results will be used for price index computation later in this section. The variable DHE represents the dummy for Midrange and High End products, and is interacted with $\log$ (Bandwidth), $\log$ (Number of ports available), $\log$ (FLASH memory), $\log$ (Processor speed), $\log$ (DRAM memory), and a dummy variable for DC power source. These interaction terms are provided to allow for varying coefficients across the lower and higher ends of the product spectrum. In our adjacent year regressions, we include year dummies interacted with product spectrum dummies for $\mathrm{SOHO}$, Low End, Midrange, and High End routers and use these variables to estimate second-period prices. Standard errors are in parentheses and are calculated using the White (1980) heteroskedasticity-robust procedure.

Table 6 shows the price indexes derived from the regressions. Pakes (2002) notes that because the parameters of a hedonic regression reflect the results of a complex equilibrium process, there is no reason to expect a positive relation between price and characteristics of goods that are thought to be desirable. Accordingly, we will not discuss the coefficient results on the hedonic regression, and focus our analysis on the price index results. We last calculate price indexes by exponentiating the dummy coefficients on the time dummies in our adjacent year regressions. As is well known, price indexes calculated using these methods are biased, and we employ the standard correction of adding to the coefficient one half times the squared standard error (Triplett 1989).

The last lines in table 6 show our composite, chain weighted, router index based on North American sales for the four router categories. This index was created by chain-weighting the four individual router indexes. Overall, router prices fell an average of 13.6 percent between 1995 and 1999. In other words, router prices fell much more rapidly than recent government estimates for the communications sector. However, comparing our results to other recent hedonic studies, prices of routers fell much more slowly than prices of computing equipment. As a comparison, BEA's Communications Equipment price index fell 1.8 percent between 1995 and 2000, while BEA's index for Computers and Peripheral Equipment fell 22.2 percent over the same period. Using pooled hedonic price regressions, Berndt and Rappaport (2001) show prices for desktop and mobile personal computers fell at an average rate of 41.1 percent and 31.4 percent over 1994-1999. Below we discuss potential reasons for these differences in the rates of 
router and computer price declines. We will also address the significant variation we observe in the rate of price declines across router classes.

- Differences between computers and routers: One reason for the difference in the rate of price declines between computers and routers may be differences in the rate of decline in semiconductors. Aizcorbe, Flamm, and Khrushid (2001) show that the prices of semiconductor inputs in computers have fallen faster than semiconductor inputs in communications equipment. Moreover, they estimate that semiconductors account for a greater share of variable costs in computers than in communications equipment. Because semiconductor prices have fallen so rapidly, this translates into larger declines in prices for computers than for routers. Using data from 1998, they show that declines in semiconductors contributed anywhere from 16.1 to 23.8 percentage points to the 40.3 percent decline in computer prices in that year. In contrast, they show semiconductors contributed between 5.7 and 10.0 percentage points to the 29.5 percent decline in LAN prices in 1998. ${ }^{23}$ They conclude that differences in semiconductor input price declines can explain almost all of the variation in price changes between computers and LAN equipment in 1998.

- Differences among classes of routers: Table 6 shows that each of the four router classes declined at significantly different rates between 1995 and 1999. In particular, Midrange prices rose 3.2 percent while prices for the other three categories fell between 16.1 and 24.7 percent. $^{24}$ We believe that differences in market structure helps to explain the different growth rates.

For one, we believe that the presence of switching costs in routers has influenced their rate of price declines. Klemperer (1995) shows how learning and compatibility costs between existing systems and new purchases can lead to switching costs in changing vendors. Such switching costs can cause buyers to exhibit "brand loyalty" and so increase the likelihood of repeat purchases from incumbent vendors. The trade press generally regards switching costs in the market for routers and switches to be significant (e.g., Tolly, 2000; Wickre, 1996; Petrosky, 1996). Forman (2002) has used discrete choice models to demonstrate the existence of switching

\footnotetext{
${ }^{23}$ Aizcorbe, Flamm, and Khurshid (2001) cite the Federal Reserve Board's Industrial Production index described in Corrado (2001). This index used the LAN price index in this paper as an input.

${ }^{24} \mathrm{We}$ believe the apparent rise in Midrange prices probably captures flatness in price declines over our sample. We carefully examined the routers and modules in this segment and found little evidence of price changes over our sample for the vast majority of products.
} 
costs in this market, showing that vendor incumbency can increase the probability of purchase from a vendor from 14 percent to 25 percent.

When switching costs are present, the seller's optimal strategy is often to set prices low in early periods to capture a large installed base of "locked-in" customers (Klemperer 1995; Farrell and Klemperer 2001). If sellers are unable to identify new and repeat customers, prices in later periods will depend on the fraction of new and repeat buyers. ${ }^{25}$ The literature generally shows that the larger the share of repeat buyers, the more likely sellers will charge high prices in later periods to reap the benefits of their installed base.

This dynamic pricing strategy is fully consistent with our results. The product lines in the midrange segment are among the oldest in the market. Moreover, they are the products sold to Cisco's most faithful customers-large enterprises (Bunnell 2000). We believe that Cisco maintained flat prices in Midrange routers to capture rents among its most loyal customers. In contrast, the High End router market was new and growing rapidly over 1995-1999. Cisco had a large market share, however most growth came from new customers. In contrast to the Midrange market, prices fell rapidly (-16.1 percent). SOHO and Low End products, because of their simplicity, had among the lowest switching costs.

Second, the effects of high concentration in the Midrange segment may have contributed to the flatness in prices. Table 3b shows that in 1996 and 1999, Cisco's market share in the Midrange segment was 66.6 percent and 79.6 percent: Cisco's second highest for both years. Although it had a higher market share in High End routers, new product entry from smaller players such as Juniper Communications limited Cisco's market power. If market shares and market power were greatest in the Midrange segment, then most static and dynamic theories of oligopoly pricing would suggest that price-cost margins in this market would be elevated. In contrast, the most competitive router segment is SOHO, and that is the category that has the highest average price declines.

\footnotetext{
${ }^{25}$ Sellers will sometimes be able to identify new and repeat buyers. When this is the case, the optimal strategy is for sellers to charge high prices to repeat buyers to exploit their ex-post absence of outside options. This alternative scenario is also fully consistent with the pattern of prices we observe in the market.
} 


\section{Price Indexes for Switches}

\section{IV.1. Data and Characteristics Selection for Switches}

The analysis of switches closely follows that of routers, with some exceptions. Because Cisco's market share is smaller in switches than it is in routers (table 3a), we thought it was important to obtain data from additional vendors. Moreover, because switches are simpler devices than routers, traditional data sources contained sufficient information. We used price and characteristics data from Datapro's "Comparison Column Reports”, a service that compares switches from a variety of vendors. The reports typically list a series of switches across columns and the rows in the reports contain information on the characteristics of the switches, such as number of ports, interfaces, et cetera. As a check, we compared the Datapro data against Cisco product catalogues for Cisco switches and generally found that the two sources of data for Cisco switches agreed.

Several problems were encountered in collecting this data. First, not all reports contained the same information on characteristics, and many observations had to be dropped due to inadequate information on the characteristics of the switch. Second, we were not able to obtain data for 1998. Third, our sample in 1997 is small (18 observations). ${ }^{26}$ Finally, like routers, the prices in the reports are list prices rather than transaction prices. We were able to gather usable data for a total of 366 observations from 1996 to 2000.

Table 7 presents summary statistics for the LAN switch database. Like routers, measures of performance are difficult to come by. We were unable to collect data on the type of processor or memory chip in switches as we did in routers. However, we were able to obtain information on the number and types of interface ports in each switch. These are the primary dimensions along which speed and quality are judged in switches. For each type of interface port, we included both a dummy indicating the presence of that port type as well as the log of the number of ports available. We control for 10, 100, and 1,000 megabit Ethernet ports, FDDI (fiber distributed data interface) ports, and ATM (asynchronous transfer mode) ports.

We were also able to collect some additional data on the capabilities of switches. Switches vary by whether they have layer 3 switching capability and single mode fiber

\footnotetext{
${ }^{26}$ Entries in the comparison column reports were updated when Datapro issued a review of the product report. Entries that had not been reviewed were simply carried over from previous reports. To eliminate biases from data error, we dropped observations that were duplicates of the previous report. Many of the observations in the 1997 report were copies of the 1996 report with no change.
} 
capability. Layer 3 capability indicates that the switch is capable of performing functions on the third layer of the Open Systems Interconnection (OSI) communication model. Generally, switches operate on layer 2 of the OSI model; layer 3 capability indicates, among other things, that the switch is on the technical frontier. Single mode fiber is optical fiber used to carry a single ray of light, thus single mode fiber indicates a type of FDDI capability.

Many of the switches in our sample had a wide array of characteristics--enabling them to speak a variety of languages and operate at varying speeds. We included all switch models in the regressions and did not segment the data into classes, as we did with routers. Although there is a very wide range in speed, sophistication, and capacity across switches, we were unable to find a small number of clearly defined market segments in switches as we did in routers. ${ }^{27}$

\section{IV.2. Switch Results}

Table 8 presents the results from a pooled regression and from adjacent year regressions. ${ }^{28}$ Not shown in the table is a list of firm dummy variables. Using the dummy variables from the adjacent year regressions, we found the average annual price decrease was 21.9 percent, a faster rate of decline than that for routers. The pooled regression results generate a nearly identical result of 22.2 percent. Thus, it appears that prices for switches fell substantially faster than that for routers.

We spoke with several buyers of networking gear and they confirmed our results; they felt that switch prices have fallen faster than routers prices. Again, we feel that market structure provides one reason for the different rates of price declines. As shown in table 3a, the switch market is much less concentrated than the router market. Cisco has far less market power, and no firm is dominant in the same way that Cisco is in the router market. If firms in a competitive market price more aggressively, then this will lead to more rapid rates of price declines.

The presence of switching costs may also help to explain the pattern of price declines in the switch market. Forman (2002) has shown that switching costs can influence switch vendor selection. Figure 2 shows that the switch market achieved critical mass in 1995 and grew explosively throughout the late 1990s. If switching costs play a role in vendor selection, then the

\footnotetext{
${ }^{27} \mathrm{We}$ did experiment with different product groupings, but found no clear advantage to doing so. Additionally, the samples by year were small (especially for 1997), so dividing the sample greatly increased the standard errors of our estimates.

${ }^{28}$ Annual regressions were not run because of the small samples, especially in 1997.
} 
models described above on dynamic pricing under switching costs suggest that switch vendors will compete aggressively in the early years of the market to obtain market share and an installed base of locked-in users. In other words, the rapid price declines in switches may reflect early period market competition among Cisco, 3Com, and Nortel Networks to obtain greater ex post market power in future years.

\section{Price Indexes for LAN Cards}

The third component of local area network equipment that we examine is LAN cards, the device in a computer that is physically connected to a computer network. Like routers and switches, LAN cards vary in terms of speed and interfaces. Unlike routers and switches, LAN cards have a very small set of characteristics, and the data are fairly homogenous within each of the categories for which we have data. ${ }^{29}$

We obtained data on LAN cards comes from Dataquest, another industry consulting group and subsidiary of the Gartner Group, Inc. Dataquest tracks price and revenue for the world LAN card market; we display 1995 through 2000 data in table 9. Prices in table 9 are average prices for the relevant category, and are obtained by dividing revenue by total shipments for each year.

Because LAN cards are fairly homogenous within each category and there is little technical change within existing categories, the new goods bias is not as large as with other LAN equipment. As a result, we can use traditional matched-model indexes to measure price changes in LAN cards. We computed a chain-weighted, matched-model price index with this data. Prices for LAN cards fell an average of 18.3 percent per year between 1995 and 2000.

\section{Price Indexes for Hubs}

The final components of LAN equipment, hubs, are simple devices that have been replaced over the years by switches. We have not performed an analysis of hubs like that of routers and switches for several reasons. First, we had a difficult time in obtaining data that contained prices and characteristics. Second, the importance of hubs in total LAN expenditures has decreased over time, so we allocated our own resources in getting better measures on prices

\footnotetext{
${ }^{29}$ LAN cards do not have varying number of ports, nor do they generally have important product characteristics beyond the protocols they are able to interface with.
} 
for switches and routers. In 2000, spending on hubs accounted for only 4 percent of total LAN expenditures.

For hubs we use an admittedly crude approach. The approach examines the relationship between changes in the price per port for switches and compares that to the price per port for hubs. The reason we exploit this relationship is that we have price per port data for hubs and for switches, but no price data for hubs themselves. The price per-port measures are Fisher indexes based on data for a handful of switch and hub classes.

Figure 3 presents these data. Between 1996 and 2000, the price per-port measures for switches fell at an annual average rate of 34.7 percent whereas the price per-port measure for hubs fell 30.1 percent. We construct a price index for hubs by taking the ratio of the two Fisher per-port indexes and multiplying by the switch price index. Since the per-port index for hubs doesn't fall as fast as the per-port measure for switches, the price index for hubs doesn't fall as fast as that for switches. From 1996 to 2000, we estimate that the prices for hubs fell at an annual average rate of 19.0 percent. We admit this is the weakest result in the paper, but, as pointed out before, the nominal share of hubs in LAN equipment has been declining and became very small, so the effect of errors in our hubs index will not have a large effect on our overall results.

\section{Our LAN Price Index and Implications}

Using the results from the previous sections, we calculate that the LAN equipment price index fell at a 17 percent annual rate between 1995 and 2000, about 16 percentage points faster than if the BLS PPI for communications equipment was used.

We next used our LAN equipment index to estimate the impact this revised price index would have on real investment in the National Accounts. As we stated in the beginning of this paper, LAN equipment is a relatively small portion of private equipment and software spending. Therefore, the effects that this index would have on much larger aggregates will be limited. Nonetheless, we estimate that the real growth rate for certain investment aggregates would be boosted in non-trivial ways. For instance, the real growth of communications equipment would be boosted by an average of 2.4 percentage points a year between 1995 and 2000 by using our index. The comparable figure for total information processing equipment would be about 0.6 percentage points per year. For total non-residential investment, the average real growth rate 
would be boosted by 0.2 percentage points per year. It is important to note that the results of this paper have already been incorporated into the NIPAs, and that real growth rates for investment in communications equipment and for non-residential investment have been revised upwards as a consequence of them.

\section{Conclusions}

There is good reason to believe that prices for communications equipment are mismeasured, in part, because of rapid technological change. In this paper, we examined prices for just one area of communications equipment, LAN equipment. We found that prices fell quite quickly during the later half of the 1990s, although not as quickly as prices of computers. We found that there was a good deal of variation across various LAN categories. This variation

appears to be consistent with stories we have heard about the structure of the industry, as well as recent studies on input prices and buyer behavior in this market.

We view our research into LAN equipment pricing as one step towards better understanding what actually happened to prices for communications equipment more generally. As shown above, accurate measurement of these prices can have important implications for measurement of investment and productivity growth. 


\section{$\underline{\text { References }}$}

Aizcorbe. A., C. Corrado, and M. Doms (2000) "Constructing Price and Quantity Indexes for High Quality Goods," Working Paper, Board of Governors of the Federal Reserve System.

Aizcorbe, A., K. Flamm, and A. Khurshid (2002) "The Role of Semiconductor Inputs in IT Hardware Price Decline: Computers vs. Communications, “FEDS Working Paper 2002-37.

Berndt, E. R., Z. Griliches, and N. Rappaport (1995) "Econometric Estimates of Price Indexes for Personal Computers in the 1990's" Journal of Econometrics 68 (1): 243-268.

Berndt, E. R. and N. Rappaport (2001) "Price and Quality of Desktop and Mobile Personal Computers: A Quarter Century Historical Overview," American Economic Review 91(2): 268273.

Boskin, M., E. Dulberger, R. Gordon, Z. Griliches, and D. Jorgenson (1996) "Toward a More Accurate Measurement of the Cost of Living," Final Report to the Senate Finance Committee, December 4.

Brynjolfsson, Erik and Chris Kemerer (1996) "Network Externalities in Microcomputer Software: An Econometric Analysis of the Spreadsheet Market" Management Science 42(12): 1627-1647.

Bunnell, David (2000) Making the Cisco Connection: The Story Behind the Real Internet Superpower. New York: John Wiley and Sons.

Chwelos, P. (2001) “Approaches to Performance Measurement in Hedonic Analysis: Price Indexes for Laptop Computers in the 1990's" Working Paper, University of British Columbia.

Cole, R., C. Chen, J.A. Barquin-Stolleman, E. Dulberger, N. Helvacian, and J.H. Hodge (1986) "Quality-Adjusted Price Indexes for Computer Processors and Selected Peripheral Equipment," Survey of Current Business 66: 41-50.

Corrado, C. (2001) "Industrial Production and Capacity Utilization: The 2000 Annual Revision," Federal Reserve Bulletin, March.

Farrell, Joseph and Paul Klemperer (2001) "Coordination and Lock-in: Competition with Switching Costs and Network Effects," Working Paper, available on-line at www.paulklemperer.org.

Feenstra, Robert (1995) "Exact Hedonic Price Indexes" Review of Economics and Statistics, 77(3): 634-653.

Flamm, Kenneth (1989) "Technological Advance and Costs: Computers versus Communications" in Robert Crandall and Kenneth Flamm, eds. Changing the Rules: 
Technological Change, International Competition, and Regulation in Communications. Washington: The Brookings Institution. 13-61.

Forman, C. (2002) "Switching Costs, Network Effects, and Networking Equipment: Compatibility and Vendor Choice in the Market for LAN Equipment," Proceedings of the Twenty-Third International Conference on Information Systems, p. 685-696.

Forman, C. and M. Doms (1999) "Price Declines and Consumer Welfare Benefits in Computer Networking Equipment," Working Paper, Kellogg School of Management, Northwestern University.

Gandal, Neil (1994) "Hedonic Price Indexes for Spreadsheets and an Empirical Test of the Network Externalities Hypothesis" RAND Journal of Economics 25(1): 160-170.

Gordon, Robert J. (1990). The Measurement of Durable Goods Prices. National Bureau of Economic Research Monograph.

Gort, M. and S. Klepper (1982) "Time Paths in the Diffusion of Product Innovations," Economic Journal 92 (September): 630-653.

Grimm, Bruce (1996) “A Quality Adjusted Price Index for Digital Telephone Switches," Working Paper, Burea of Economic Analysis.

Harchaoui, Tarek and Malika Hamdad (2000) "The prices of classical recorded music: a hedonic approach" International Journal of Industrial Organization 18: 497-514.

Hausman, Jerry (1999) “Cellular Telephone, New Products, and the CPI” Journal of Business and Economic Statistics 17(2): 188-194.

Heravi, Saeed and Mick Silver (2002) "On the Stability of Hedonic Coefficients and their Implications for Quality-Adjusted Price Change Measurement," Working Paper, Cardiff Business School, Cardiff, UK.

Jorgenson, Dale and Kevin Stiroh (2000), "Raising the Speed Limit: U.S. Economic Growth in the Information Age", Brookings Papers on Economic Activity, v.0, pp. 125-211.

Klemperer, Paul (1995) "Competition when Consumers Have Switching Costs," Review of Economic Studies, 62: 515-539.

Klepper, Steven (1996) "Entry, Exit, Growth, and Innovation over the Product Life Cycle" American Economic Review 86(3): 562-583.

Luzio, E. and S. Greenstein (1995) "Measuring the Performance of a Protected Infant Industry: The Case of Brazilian Microcomputers" Review of Economics and Statistics. 622-633. 
Nelson, Randy, Tim Tanguay, and Christopher Patterson (1994) "A Quality-Adjusted Price Index for Personal Computers" Journal of Business and Economic Statistics 12(1): 23-31.

Nevo, Aviv (2001) "New Products, Quality Changes, and Welfare Measures Computed From Estimated Demand Systems" NBER Working Paper \#8425.

Pakes, Ariel (2002) "A Reconsideration of Hedonic Price Indices with an Application to PCs" NBER Working Paper \#8715.

Petrin, A. (1999) "Quantifying the Benefits of New Products: The Case of the Minivan" Working Paper, Graduate School of Business, University of Chicago.

Petrosky, Mary (1996) “Cisco pursues a vision of being all things to all users” Network World Fusion.

Shapiro, M. and D. Wilcox (1996) "Mismeasurement in the Consumer Price Index: An Evaluation," in B.S. Bernanke and J.J. Rotemberg, eds. NBER Macroeconomics Annual. Cambridge, MA: MIT Press.

Tolly, Kevin (2000) "Lack of proven switch interoperability hurts aggressors" online article on the Tolly Group web page.

Trajtenberg, M. (1989) Economic Analysis of Product Innovation: The Case of CT Scanners. Cambridge, Massachusetts: Harvard University Press.

Triplett, J. (1989) Price and Technical Change in a Capital Good: A Survey of Research on Computers. in D. Jorgenson and R. Landau, eds. Technology and Capital Formation. Cambridge, MA: MIT Press. 127-213.

White, H. (1980) "A heteroskedasticity-consistent covariance matrix estimator and a direct test for heteroskedasticity” Econometrica 48: 817-838.

Wickre, Paul (1996) "Stick to true standards-based solutions” Network World Fusion, 1996. 
Figure 1

A Simplified Version of a Local Area Network

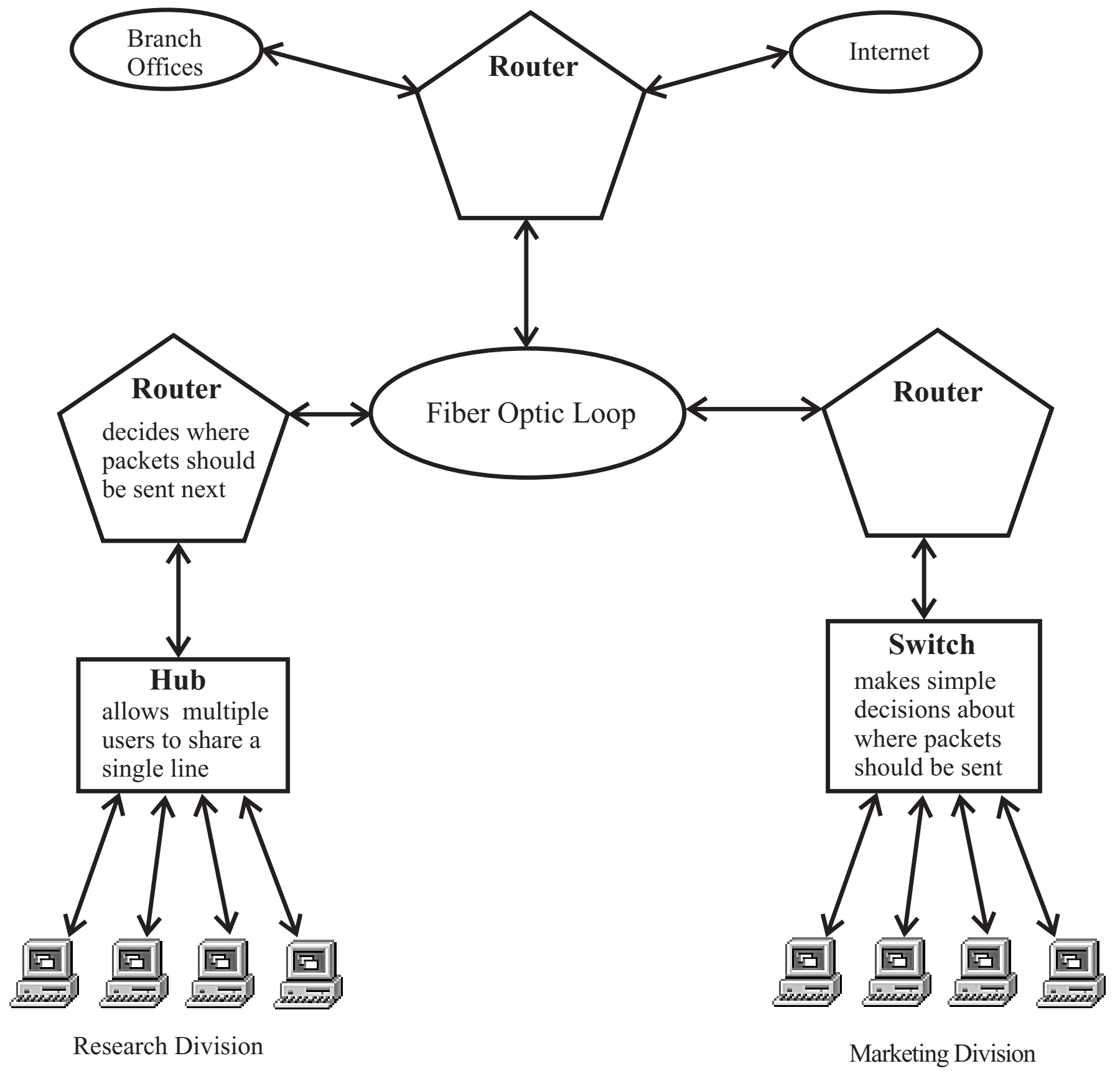


Figure 2: End User Spending on Local Area Network Equipment

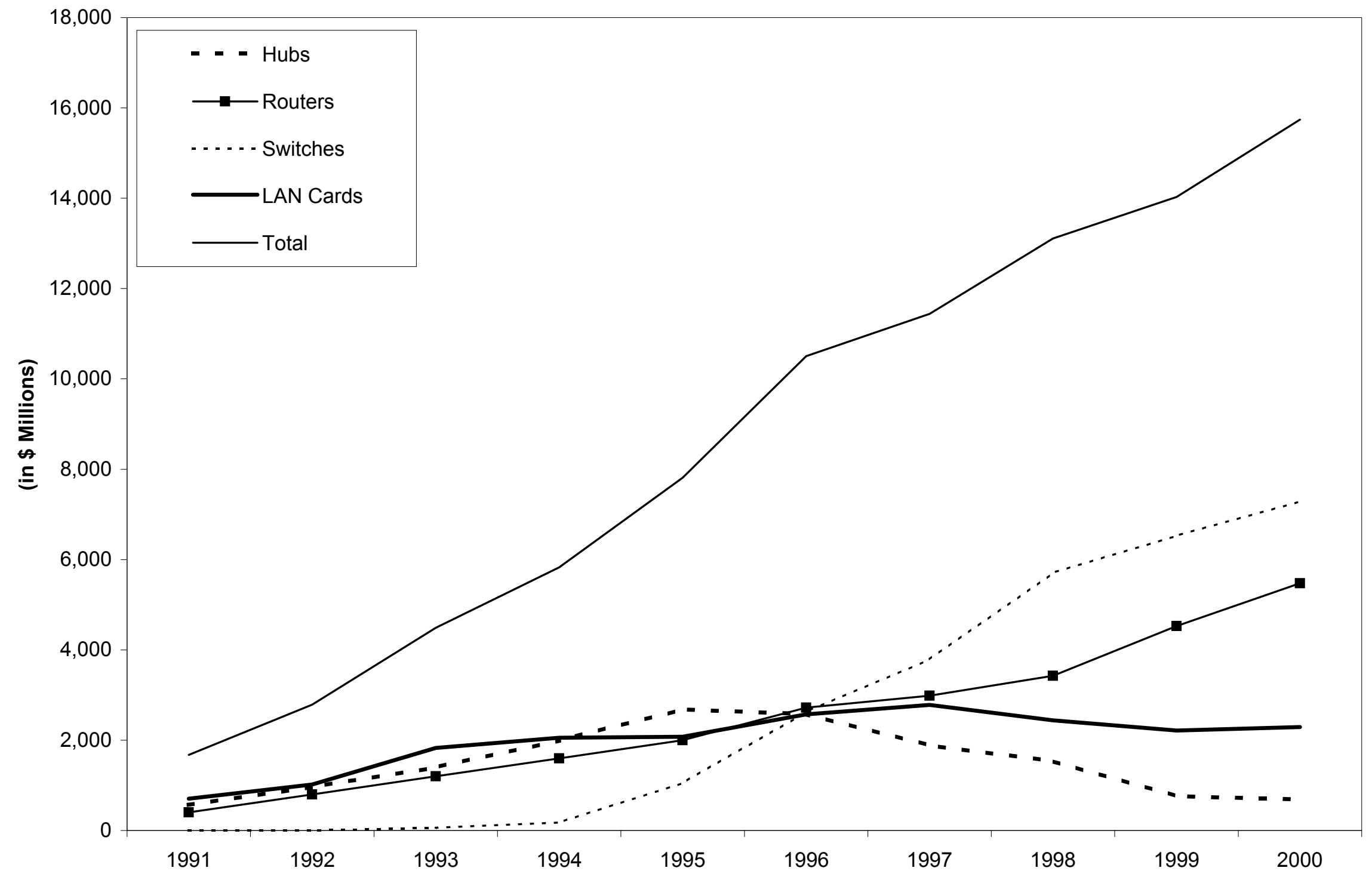




\section{Figure 3: Price Indexes for Hubs and Switches}

(Index $1996=100)$

- - - Hedonic Switch Price Index, AAGR = -21.9\%

Chain-Weighted Price Per Port Switch Index, AAGR $=-34.7 \%$

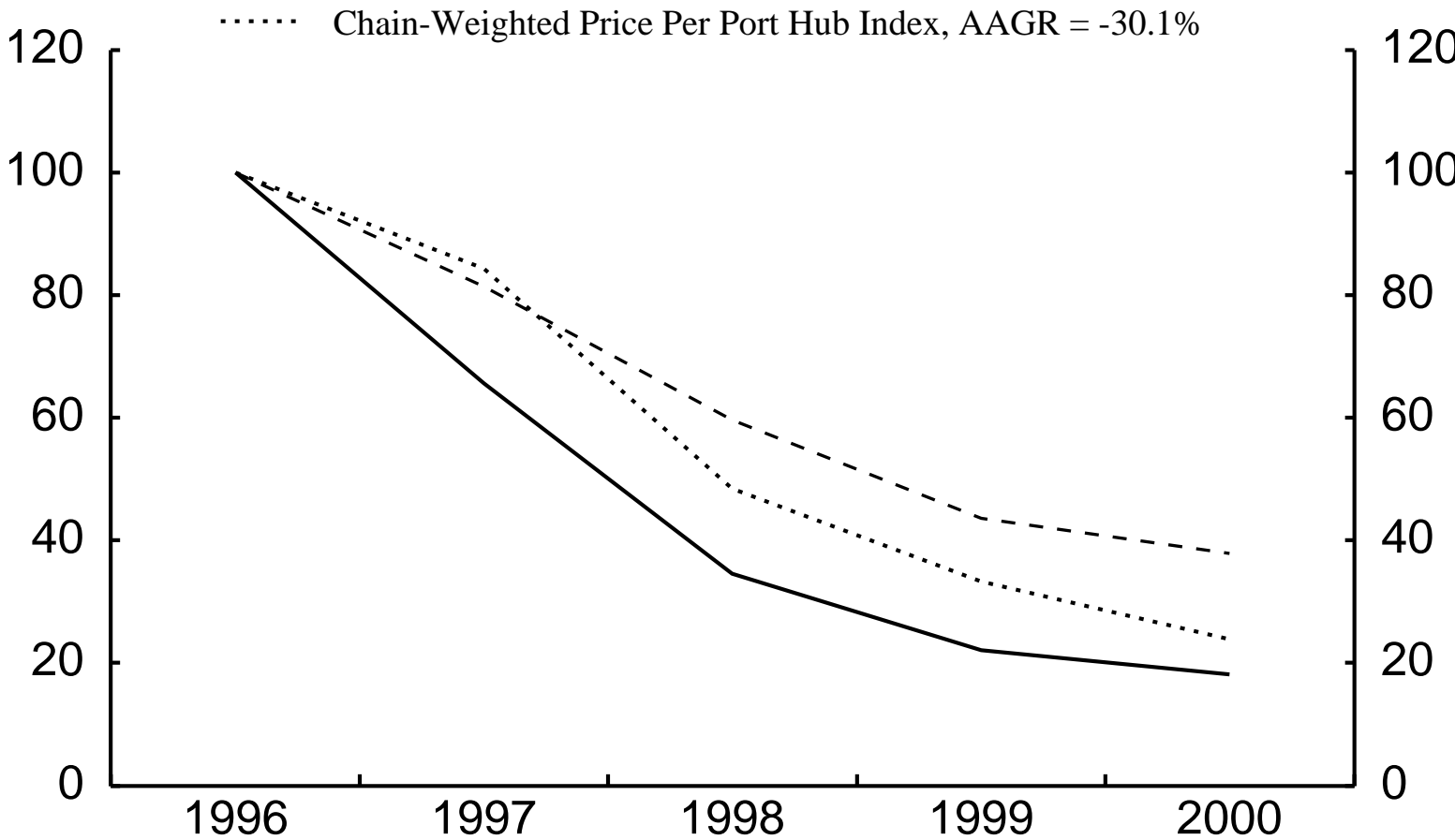

- - - Hedonic Switch Price Index, Percent Change From Preceding Year

- Chain-Weighted Price Per Port Switch Index, Percent Change From Preceding Year

-10 Chain-Weighted Price Per Port Hub Index, Percent Change From Preceding Year

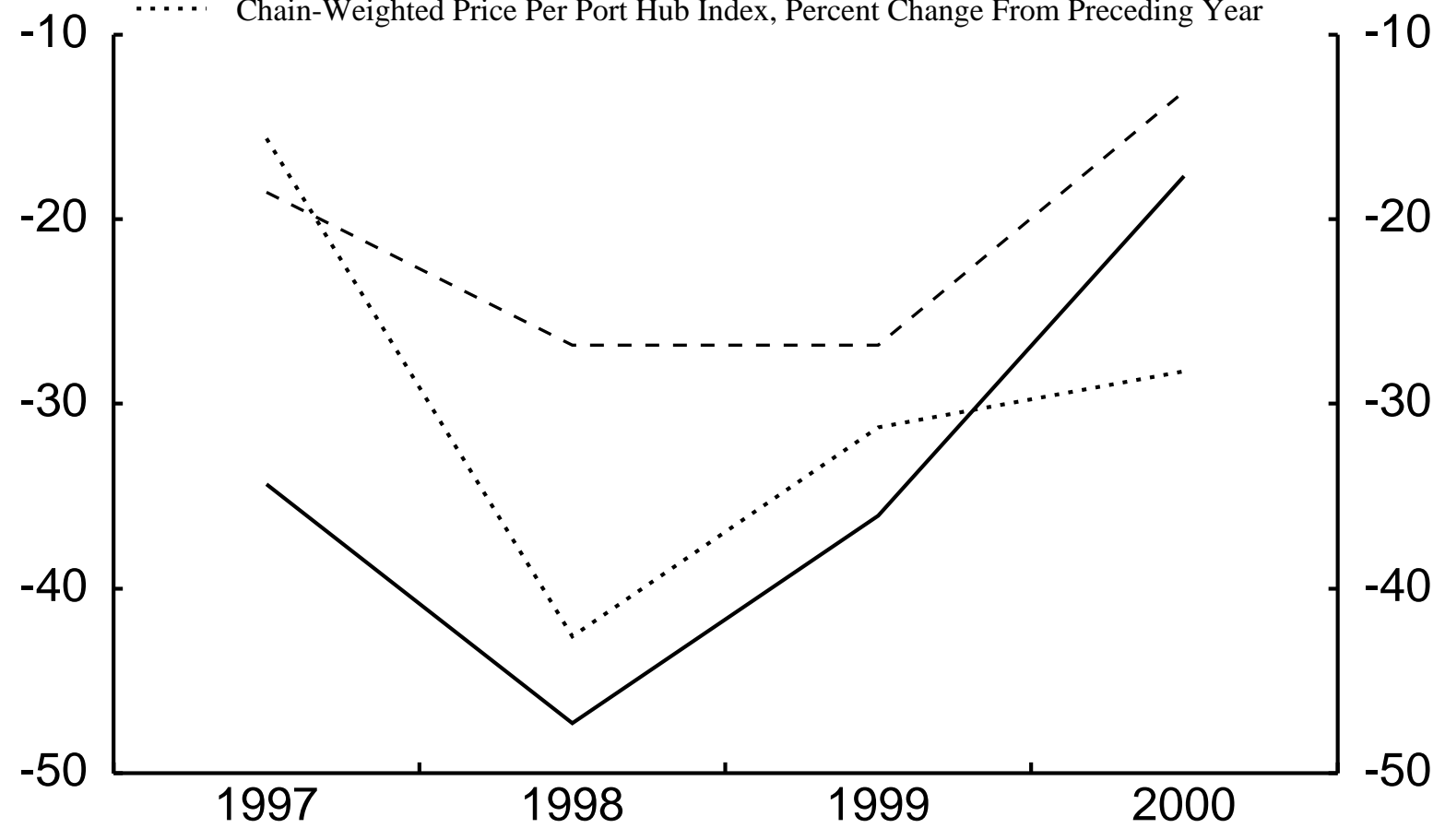


Table 1

Investment in Information Processing Equipment and Software Billions of Dollars

Average Annual

Growth Rates (\%)

\begin{tabular}{|c|c|c|c|c|c|c|c|c|c|c|c|c|}
\hline & 1991 & 1992 & 1993 & 1994 & 1995 & 1996 & 1997 & 1998 & 1999 & 2000 & $1991-2000$ & $1995-2000$ \\
\hline Total information processing & 181.4 & 197.5 & 215.0 & 233.7 & 262.0 & 287.3 & 325.2 & 363.4 & 402.3 & 446.9 & 10.5 & 11.3 \\
\hline Software & 56.6 & 60.8 & 69.4 & 75.5 & 83.5 & 95.1 & 116.5 & 140.1 & 162.5 & 179.4 & 13.7 & 16.5 \\
\hline Communication equipment & 45.7 & 47.8 & 48.2 & 54.7 & 60.0 & 65.6 & 73.7 & 81.2 & 93.7 & 116.6 & 11.0 & 14.2 \\
\hline LAN Equipment & 1.7 & 2.8 & 4.5 & 5.8 & 7.8 & 10.5 & 11.4 & 13.1 & 14.0 & 15.7 & 28.3 & 15.1 \\
\hline Computers and peripheral equipment & 37.7 & 43.6 & 47.2 & 51.3 & 64.6 & 70.9 & 79.6 & 84.2 & 90.4 & 93.3 & 10.6 & 7.6 \\
\hline Instruments & 24.2 & 26.6 & 28.7 & 29.3 & 31.3 & 33.3 & 33.3 & 36.3 & 38.2 & 40.6 & 5.9 & 5.3 \\
\hline Other & 17.2 & 18.7 & 21.6 & 22.9 & 22.5 & 22.4 & 22.1 & 21.6 & 17.5 & 17.0 & -0.1 & -5.4 \\
\hline
\end{tabular}

Source: National Income and Product Accounts and authors' calculations 
Table 2: Official Price Measures for Communications Equipment and Computers (Average Annual Percent Change)

\begin{tabular}{lrrr} 
& $\mathbf{1 9 9 0 - 1 9 9 5}$ & $\mathbf{1 9 9 5 - 2 0 0 0}$ & $\mathbf{1 9 9 0 - 2 0 0 0}$ \\
\hline BLS PPI Communications Equipment & 1.17 & -0.63 & 0.27 \\
BLS PPI "Other Data Communications Equipment" & 1.63 & 0.50 & 1.02 \\
BEA Communication Equipment 1 $_{\text {BEA Computers and Peripheral Equipment }}$ & -1.49 & -1.84 & -1.66 \\
BE & -13.44 & -22.22 & -17.95
\end{tabular}

1. This is the BEA deflator before the LAN results were incorporated. 
Table 3a

Market Share of Four Largest Firms by LAN Equipment Type

\begin{tabular}{|c|c|c|c|c|}
\hline & \multicolumn{2}{|l|}{1996} & \multicolumn{2}{|c|}{1999} \\
\hline & Firm & Market Share & Firm & Market Share \\
\hline \multirow[t]{4}{*}{ Routers } & Cisco Systems & $54.6 \%$ & Cisco Systems & $77.0 \%$ \\
\hline & Bay Networks Inc. & $10.3 \%$ & Nortel Networks & $6.9 \%$ \\
\hline & Ascend Communications Inc. & $9.2 \%$ & Fujitsu & $2.5 \%$ \\
\hline & 3Com & $6.4 \%$ & 3Com & $2.4 \%$ \\
\hline \multirow[t]{4}{*}{ Switches } & Cisco Systems & $29.6 \%$ & Cisco Systems & $46.8 \%$ \\
\hline & 3Com & $21.2 \%$ & $3 \mathrm{Com}$ & $12.6 \%$ \\
\hline & Cabletron Systems Inc. & $11.0 \%$ & Nortel Networks & $8.7 \%$ \\
\hline & Bay Networks Inc. & $9.9 \%$ & Fore Systems & $6.4 \%$ \\
\hline \multirow[t]{4}{*}{ LAN Cards } & 3Com & $33.2 \%$ & 3Com & $35.4 \%$ \\
\hline & IBM & $13.7 \%$ & Intel & $23.2 \%$ \\
\hline & Standard Microsystems Inc. & $6.9 \%$ & IBM & $4.9 \%$ \\
\hline & Madge Networks & $5.8 \%$ & Xircom & $4.7 \%$ \\
\hline \multirow[t]{4}{*}{ Hubs } & Bay Networks Inc. & $24.5 \%$ & 3Com & $30.3 \%$ \\
\hline & 3Com & $18.8 \%$ & Nortel Networks & $16.7 \%$ \\
\hline & Cabletron Systems Inc. & $14.7 \%$ & D-Link Systems & $7.4 \%$ \\
\hline & IBM & $4.8 \%$ & Intel & $4.3 \%$ \\
\hline
\end{tabular}

Source: Dataquest

Table 3b

Cisco Router Market Shares by Segment

\begin{tabular}{lrlr} 
& 1996 & \multicolumn{2}{c}{1999} \\
Router Segment & Market Share & Router Segment & Market Share \\
\hline SOHO & $29.4 \%$ & SOHO & $53.0 \%$ \\
Low End & $55.1 \%$ & Low End & $69.8 \%$ \\
Midrange & $66.6 \%$ & Midrange & $79.6 \%$ \\
High End & $67.8 \%$ & High End & $87.2 \%$ \\
\hline
\end{tabular}

Source: Dataquest 
Table 4(a): Summary Statistics for Routers

Router Characteristics by Market Segment

\begin{tabular}{|c|c|c|c|c|}
\hline & Mean & Std Dev & Minimum & Maximum \\
\hline \multicolumn{5}{|c|}{ Small Office/Home Office (SOHO) Routers } \\
\hline Price $(\$)$ & 769 & 244 & 395 & 1,399 \\
\hline Bandwidth (Mbps) & 17.8 & 13.1 & 10.1 & 40.2 \\
\hline Number of ports available & 0.0 & 0.0 & 0.0 & 0.0 \\
\hline FLASH memory (MB) & 1.3 & 2.4 & 0.0 & 8.0 \\
\hline Processor speed (MHz) & 27.9 & 5.2 & 16.0 & 33.0 \\
\hline DRAM memory (MB) & 2.8 & 1.8 & 1.0 & 8.0 \\
\hline DC power source & 0.00 & 0.00 & 0.00 & 0.00 \\
\hline $1=\mathrm{YES} \quad 0=\mathrm{NO}$ & & & & \\
\hline \multicolumn{5}{|l|}{ Low End Routers } \\
\hline Price $(\$)$ & 4,301 & 1,861 & 895 & 8,195 \\
\hline Bandwidth (Mbps) & 54.3 & 63.9 & 1.5 & 372.2 \\
\hline Number of ports available & 1.0 & 0.9 & 0.0 & 3.0 \\
\hline FLASH memory (MB) & 6.9 & 1.8 & 2.0 & 8.0 \\
\hline Processor speed (MHz) & 31.7 & 9.9 & 20.0 & 50.0 \\
\hline DRAM memory (MB) & 14.4 & 10.1 & 2.0 & 24.0 \\
\hline DC power source & 0.43 & 0.50 & 0.00 & 1.00 \\
\hline $1=\mathrm{YES} \quad 0=\mathrm{NO}$ & & & & \\
\hline \multicolumn{5}{|l|}{ Midrange Routers } \\
\hline Price $(\$)$ & 41,526 & 16,707 & 4,600 & 78,550 \\
\hline Bandwidth (Mbps) & 284.6 & 187.5 & 1.0 & 630.0 \\
\hline Number of ports available & 3.7 & 0.6 & 2.0 & 4.0 \\
\hline FLASH memory (MB) & 14.4 & 6.1 & 4.0 & 20.0 \\
\hline Processor speed (MHz) & 157.3 & 59.2 & 40.0 & 263.0 \\
\hline DRAM memory (MB) & 28.4 & 7.6 & 8.0 & 32.0 \\
\hline DC power source & 0.12 & 0.33 & 0.00 & 1.00 \\
\hline $1=\mathrm{YES} \quad 0=\mathrm{NO}$ & & & & \\
\hline \multicolumn{5}{|l|}{ High End Routers } \\
\hline Price $(\$)$ & 85,900 & 47,705 & 38,200 & 326,900 \\
\hline Bandwidth (Mbps) & 539.7 & 258.9 & 7.5 & 1460.0 \\
\hline Number of ports available & 6.2 & 1.6 & 3.0 & 11.0 \\
\hline FLASH memory (MB) & 16.8 & 3.6 & 4.0 & 20.0 \\
\hline Processor speed (MHz) & 187.2 & 66.3 & 25.0 & 300.0 \\
\hline DRAM memory (MB) & 30.8 & 4.3 & 16.0 & 32.0 \\
\hline DC power source & 0.00 & 0.00 & 0.00 & 0.00 \\
\hline
\end{tabular}


Table 4 (b)

Sample Means of Dummy Variables

$\begin{array}{llll}1995 \text { Dummy } & 0.020 & \text { SOHO Dummy } & 0.008 \\ 1996 \text { Dummy } & 0.057 & \text { Low End Dummy } & 0.069 \\ 1998 \text { Dummy } & 0.254 & \text { Midrange Dummy } & 0.465 \\ 1999 \text { Dummy } & 0.669 & \text { High End Dummy } & 0.458 \\ & & \begin{array}{l}\text { Dummy for Midrange } \\ \text { or High End }\end{array} & 0.923\end{array}$


Table 5: Adjacent Year Hedonic Regression Models for Routers

\begin{tabular}{|c|c|c|c|}
\hline Variable & $1995-1996$ & 1996-1998 & 1998-1999 \\
\hline SOHO Dummy & $\begin{array}{l}5.254 \\
(0.195)\end{array}$ & $\begin{array}{l}4.874 \\
(1.303)\end{array}$ & $\begin{array}{l}8.354 \\
(0.447)\end{array}$ \\
\hline Low End Dummy & $\begin{array}{l}6.267 \\
(0.718)\end{array}$ & $\begin{array}{l}3.919 \\
(1.682)\end{array}$ & $\begin{array}{l}8.513 \\
(0.493)\end{array}$ \\
\hline Midrange Dummy & $\begin{array}{l}7.755 \\
(0.126)\end{array}$ & $\begin{array}{l}6.341 \\
(0.125)\end{array}$ & $\begin{array}{l}6.515 \\
(0.121)\end{array}$ \\
\hline High End Dummy & $\begin{array}{l}9.113 \\
(0.168)\end{array}$ & $\begin{array}{l}6.986 \\
(0.139)\end{array}$ & $\begin{array}{l}6.632 \\
(0.129)\end{array}$ \\
\hline Year Dummy * SOHO Dummy & $\begin{array}{l}0.013 \\
(0.068)\end{array}$ & $\begin{array}{r}-0.934 \\
(0.247)\end{array}$ & $\begin{array}{r}-0.256 \\
(0.126)\end{array}$ \\
\hline Year Dummy * Low End Dummy & $\begin{array}{l}0.181 \\
(0.089)\end{array}$ & $\begin{array}{r}-0.995 \\
(0.221)\end{array}$ & $\begin{array}{r}-0.078 \\
(0.054)\end{array}$ \\
\hline Year Dummy * Midrange Dummy & $\begin{array}{l}0.119 \\
(0.032)\end{array}$ & $\begin{array}{l}0.005 \\
(0.042)\end{array}$ & $\begin{array}{r}-0.001 \\
(0.013)\end{array}$ \\
\hline Year Dummy * High End Dummy & $\begin{array}{r}-0.082 \\
(0.028)\end{array}$ & $\begin{array}{r}-0.445 \\
(0.040)\end{array}$ & $\begin{array}{r}-0.177 \\
(0.015)\end{array}$ \\
\hline $\log ($ Bandwidth) & $\begin{array}{l}0.229 \\
(0.048)\end{array}$ & $\begin{array}{l}0.189 \\
(0.047)\end{array}$ & $\begin{array}{l}0.042 \\
(0.014)\end{array}$ \\
\hline DHE * $\log$ (Bandwidth) & $\begin{array}{r}-0.045 \\
(0.049)\end{array}$ & $\begin{array}{r}-0.035 \\
(0.049)\end{array}$ & $\begin{array}{l}0.098 \\
(0.015)\end{array}$ \\
\hline log(Number of ports available) & $\begin{array}{l}0.439 \\
(0.069)\end{array}$ & $\begin{array}{l}0.433 \\
(0.053)\end{array}$ & $\begin{array}{l}0.368 \\
(0.049)\end{array}$ \\
\hline DHE * $\log$ (Number of ports availablı & $\begin{array}{l}0.482 \\
(0.076)\end{array}$ & $\begin{array}{l}0.576 \\
(0.072)\end{array}$ & $\begin{array}{l}0.795 \\
(0.064)\end{array}$ \\
\hline $\log$ (FLASH Memory) & $\begin{array}{r}-0.363 \\
(0.385)\end{array}$ & $\begin{array}{l}1.055 \\
(0.359)\end{array}$ & $\begin{array}{l}0.212 \\
(0.100)\end{array}$ \\
\hline DHE * $\log ($ FLASH Memory) & $\begin{array}{r}-0.441 \\
(0.387)\end{array}$ & $\begin{array}{r}-1.213 \\
(0.362)\end{array}$ & $\begin{array}{r}-0.025 \\
(0.103)\end{array}$ \\
\hline $\log ($ Processor speed) & $\begin{array}{l}0.483 \\
(0.000)\end{array}$ & $\begin{array}{l}0.344 \\
(0.382)\end{array}$ & $\begin{array}{r}-0.767 \\
(0.122)\end{array}$ \\
\hline DHE * $\log ($ Processor speed) & $\begin{array}{r}-0.241 \\
(0.025)\end{array}$ & $\begin{array}{r}-0.125 \\
(0.383)\end{array}$ & $\begin{array}{l}1.152 \\
(0.123)\end{array}$ \\
\hline log(DRAM Memory) & $\begin{array}{r}-0.573 \\
(0.117)\end{array}$ & $\begin{array}{l}0.557 \\
(0.062)\end{array}$ & $\begin{array}{l}0.645 \\
(0.044)\end{array}$ \\
\hline DHE * log(DRAM Memory) & $\begin{array}{l}0.630 \\
(0.131)\end{array}$ & $\begin{array}{r}-0.208 \\
(0.087)\end{array}$ & $\begin{array}{r}-0.920 \\
(0.063)\end{array}$ \\
\hline $\begin{array}{l}\text { DC power source } \\
1=\text { YES } 0=\text { NO }\end{array}$ & $\begin{array}{l}0.139 \\
(0.073)\end{array}$ & $\begin{array}{l}0.171 \\
(0.058)\end{array}$ & $\begin{array}{l}0.150 \\
(0.031)\end{array}$ \\
\hline $\begin{array}{l}\text { DHE * DC power source } \\
1=\text { YES } 0=\text { NO }\end{array}$ & $\begin{array}{r}-0.056 \\
(0.079)\end{array}$ & $\begin{array}{r}-0.213 \\
(0.071)\end{array}$ & $\begin{array}{r}-0.185 \\
(0.043)\end{array}$ \\
\hline $\begin{array}{l}\mathbf{N} \\
\mathrm{R}^{2}\end{array}$ & $\begin{array}{c}399 \\
0.9802\end{array}$ & $\begin{array}{c}1,595 \\
0.9204\end{array}$ & $\begin{array}{c}4,744 \\
0.9174\end{array}$ \\
\hline
\end{tabular}


Table 6

Price Indexes For Routers Based on Adjacent Year Regressions

\begin{tabular}{lrrrrr} 
& 1995 & 1996 & 1998 & 1999 & A.A.G.R. $^{1}$ \\
\cline { 2 - 6 } SOHO Index & 1.000 & 1.015 & 0.411 & 0.321 & -24.72 \\
$\quad$ (Percent change) & & 1.50 & -59.48 & -21.94 & \\
& & & & & \\
Low End Index & 1.000 & 1.203 & 0.456 & 0.422 & -19.40 \\
$\quad$ (Percent change) & & 20.26 & -62.11 & -7.39 & \\
& & & & & \\
Midrange Index & 1.000 & 1.127 & 1.133 & 1.133 & 3.16 \\
$\quad$ (Percent change) & & 12.67 & 0.59 & -0.06 & \\
High End Index & 1.000 & 0.921 & 0.591 & 0.495 & -16.11 \\
$\quad$ (Percent change) & & -7.88 & -35.85 & -16.18 & \\
& & & & & -13.62 \\
\hline $\begin{array}{c}\text { All Routers Index }{ }^{2} \\
\text { (Percent change) }\end{array}$ & 1.000 & 1.066 & 0.622 & 0.557 & \\
\hline
\end{tabular}

1. Average annual growth rate.

2. The "All Routers Index" was created by chain-weighting the four component indexes. 
Table 7: Summary Statistics for LAN Switches

\begin{tabular}{|c|c|c|c|c|}
\hline Variable & Mean & Std Dev & Minimum & Maximum \\
\hline 1996 Dummy & 0.347 & 0.477 & 0 & 1 \\
\hline 1997 Dummy & 0.049 & 0.216 & 0 & 1 \\
\hline 1999 Dummy & 0.230 & 0.422 & 0 & 1 \\
\hline 2000 Dummy & 0.374 & 0.485 & 0 & 1 \\
\hline $\begin{array}{l}10 \text { MBPS Ethernet } \\
1=\text { YES } 0=\text { NO }\end{array}$ & 0.791 & 0.407 & 0 & 1 \\
\hline log(number of 10 MBPS ports) & 2.114 & 1.305 & 0 & 6.223 \\
\hline $\begin{array}{l}100 \text { MBPS Ethernet } \\
1=\text { YES } 0=\text { NO }\end{array}$ & 0.558 & 0.497 & 0 & 1 \\
\hline $\log ($ number of 100 MBPS ports) & 0.458 & 1.010 & 0 & 4.382 \\
\hline $\begin{array}{l}1,000 \text { MBPS Ethernet } \\
1=\text { YES } 0=\text { NO }\end{array}$ & 0.228 & 0.420 & 0 & 1 \\
\hline $\log ($ number of 1,000 MBPS ports) & 0.172 & 0.513 & 0 & 2.485 \\
\hline $\begin{array}{l}\text { FDDI Capability } \\
1=\text { YES } \quad 0=\text { NO }\end{array}$ & 0.236 & 0.425 & 0 & 1 \\
\hline Number of FDDI ports & 1.108 & 9.205 & 0 & 168 \\
\hline $\begin{array}{l}\text { ATM Capability } \\
1=\text { YES } 0=\text { NO }\end{array}$ & 0.149 & 0.357 & 0 & 1 \\
\hline Number of ATM Interfaces & 0.125 & 0.639 & 0 & 10 \\
\hline $\begin{array}{l}\text { Layer } 3 \text { Capability } \\
1=\text { YES } 0=\text { NO }\end{array}$ & 0.379 & 0.486 & 0 & 1 \\
\hline $\begin{array}{l}\text { Single Mode Fiber Capability } \\
1=\text { YES } \quad 0=\text { NO }\end{array}$ & 0.014 & 0.116 & 0 & 1 \\
\hline
\end{tabular}


Table 8: Hedonic Regression Models for LAN Switches

\begin{tabular}{|c|c|c|c|c|}
\hline & $1996-2000$ & 1996-1997 & 1997-1999 & $1999-2000$ \\
\hline \multirow[t]{2}{*}{1997 Dummy } & -0.180 & -0.189 & NA & NA \\
\hline & $(0.128)$ & $(0.121)$ & & \\
\hline \multirow[t]{2}{*}{1999 Dummy } & -0.900 & NA & -0.572 & NA \\
\hline & $(0.11)$ & & $(0.208)$ & \\
\hline \multirow[t]{2}{*}{2000 Dummy } & -1.005 & NA & NA & -0.227 \\
\hline & $(0.096)$ & & & $(0.105)$ \\
\hline \multirow{2}{*}{$\begin{array}{l}10 \text { MBPS Ethernet } \\
1=\text { YES } 0=\text { NO }\end{array}$} & -1.263 & -0.829 & -1.029 & -1.665 \\
\hline & $(0.169)$ & $(0.202)$ & $(0.373)$ & $(0.244)$ \\
\hline \multirow[t]{2}{*}{ log(number of 10 MBPS ports) } & 0.391 & 0.143 & 0.402 & 0.595 \\
\hline & $(0.048)$ & $(0.057)$ & $(0.111)$ & $(0.069)$ \\
\hline \multirow{2}{*}{$\begin{array}{l}100 \text { MBPS Ethernet } \\
1=\text { YES } 0=\text { NO }\end{array}$} & -0.284 & -0.302 & -0.105 & -0.091 \\
\hline & $(0.075)$ & $(0.083)$ & $(0.185)$ & $(0.112)$ \\
\hline \multirow[t]{2}{*}{$\log$ (number of 100 MBPS ports) } & 0.119 & 0.143 & 0.083 & 0.112 \\
\hline & $(0.047)$ & $(0.089)$ & $(0.086)$ & $(0.056)$ \\
\hline \multirow{2}{*}{$\begin{array}{l}1,000 \text { MBPS Ethernet } \\
1=\text { YES } 0=\text { NO }\end{array}$} & 0.419 & NA & 0.159 & 0.367 \\
\hline & $(0.113)$ & & $(0.235)$ & $(0.126)$ \\
\hline \multirow[t]{2}{*}{$\log$ (number of 1,000 MBPS ports) } & 0.307 & NA & 0.45 & 0.34 \\
\hline & $(0.082)$ & & $(0.15)$ & $(0.088)$ \\
\hline \multirow{2}{*}{$\begin{array}{l}\text { FDDI Capability } \\
1=\text { YES } 0=\text { NO }\end{array}$} & 0.192 & 0.091 & 0.219 & 0.329 \\
\hline & $(0.085)$ & $(0.080)$ & $(0.19)$ & $(0.181)$ \\
\hline \multirow[t]{2}{*}{ Number of FDDI ports } & -0.012 & -0.005 & -0.013 & -0.028 \\
\hline & $(0.004)$ & $(0.003)$ & $(0.005)$ & $(0.021)$ \\
\hline ATM Capability & 0.047 & -0.051 & 0.359 & 0.872 \\
\hline $1=$ YES $0=\mathrm{NO}$ & $(0.108)$ & $(0.105)$ & $(0.309)$ & $(0.236)$ \\
\hline \multirow[t]{2}{*}{ Number of ATM Interfaces } & 0.247 & 0.216 & -0.394 & -0.466 \\
\hline & $(0.056)$ & $(0.046)$ & $(0.431)$ & $(0.305)$ \\
\hline \multirow{2}{*}{$\begin{array}{l}\text { Layer } 3 \text { Capability } \\
1=\text { YES } 0=\text { NO }\end{array}$} & 0.529 & 0.339 & 0.554 & 0.694 \\
\hline & $(0.084)$ & $(0.099)$ & $(0.175)$ & $(0.120)$ \\
\hline \multirow{2}{*}{$\begin{array}{l}\text { Single Mode Fiber Capability } \\
1=\text { YES } \quad 0=\text { NO }\end{array}$} & 1.203 & 1.223 & 1.198 & 1.106 \\
\hline & $(0.295)$ & $(0.452)$ & $(0.593)$ & $(0.421)$ \\
\hline $\mathbf{N}$ & 366 & 145 & 101 & 220 \\
\hline $\mathbf{R}^{2}$ & 0.740 & 0.537 & 0.678 & 0.796 \\
\hline
\end{tabular}


Table 9

Average Price and Revenue for Different Types of LAN Cards

\begin{tabular}{|c|c|c|c|c|c|c|c|}
\hline & 1995 & 1996 & 1997 & 1998 & 1999 & 2000 & $\begin{array}{l}\text { Average annual } \\
\text { growth rate } \\
\text { (percent) }\end{array}$ \\
\hline \multicolumn{8}{|l|}{ 10-Mbps } \\
\hline Revenue (\$ millions) & 2,651 & 2,836 & 1,990 & 886 & 478 & 278 & \\
\hline Price $(\$ /$ card $)$ & 115 & 101 & 73 & 51 & 41 & 37 & -20.2 \\
\hline \multicolumn{8}{|l|}{ 100-Mbps } \\
\hline Revenue & 142 & 736 & 1,879 & 2,582 & 2,826 & 3,023 & \\
\hline Price & 199 & 143 & 110 & 79 & 66 & 56 & -22.4 \\
\hline \multicolumn{8}{|l|}{ 1,000-Mbps } \\
\hline Revenue & & & 2 & 34 & 70 & 152 & \\
\hline Price & & & 2,111 & 850 & 735 & 681 & -31.4 \\
\hline \multicolumn{8}{|l|}{ Token-Ring } \\
\hline Revenue & 1,236 & 1,131 & 1,099 & 843 & 472 & 350 & \\
\hline Price & 310 & 283 & 228 & 196 & 169 & 174 & -10.9 \\
\hline \multicolumn{8}{|l|}{ FDDI } \\
\hline Revenue & 136 & 160 & 121 & 84 & 51 & 26 & \\
\hline Price & 1,123 & 1,069 & 904 & 838 & 751 & 731 & -8.2 \\
\hline \multicolumn{8}{|l|}{ ATM } \\
\hline Revenue & 43 & 66 & 79 & 98 & 73 & 75 & \\
\hline Price & 964 & 614 & 653 & 562 & 432 & 437 & -14.7 \\
\hline \multicolumn{8}{|l|}{ Wireless } \\
\hline Revenue & & & 105 & 188 & 316 & 488 & \\
\hline Price & & & 327 & 340 & 275 & 250 & -8.6 \\
\hline \multicolumn{8}{|c|}{ Matched Model Price Index } \\
\hline & 1.00 & 0.87 & 0.66 & 0.49 & 0.41 & 0.36 & -18.3 \\
\hline
\end{tabular}

Reported data is for the world market. 